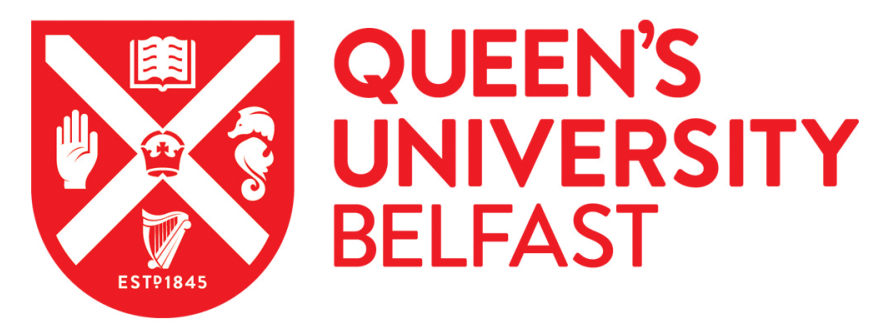

\title{
Psychological distress among survivors of esophageal cancer: the role of illness cognitions and coping
}

Dempster, M., McCorry, N. K., Brennan, E., Donnelly, M., Murray, L., \& Johnston, B. T. (2012). Psychological distress among survivors of esophageal cancer: the role of illness cognitions and coping. Diseases of the Esophagus, 25(3), 222-227. https://doi.org/10.1111/j.1442-2050.2011.01233.x

\section{Published in:}

Diseases of the Esophagus

\section{Document Version:}

Peer reviewed version

Queen's University Belfast - Research Portal:

Link to publication record in Queen's University Belfast Research Portal

Publisher rights

( 2011 Copyright the Authors. This work is made available online in accordance with the publisher's policies. Please refer to any applicable terms of use of the publisher.

\section{General rights}

Copyright for the publications made accessible via the Queen's University Belfast Research Portal is retained by the author(s) and / or other copyright owners and it is a condition of accessing these publications that users recognise and abide by the legal requirements associated with these rights.

Take down policy

The Research Portal is Queen's institutional repository that provides access to Queen's research output. Every effort has been made to ensure that content in the Research Portal does not infringe any person's rights, or applicable UK laws. If you discover content in the Research Portal that you believe breaches copyright or violates any law, please contact openaccess@qub.ac.uk. 
Psychological Distress among Survivors of Esophageal Cancer: the Role of Illness Cognitions and Coping

Running title: Distress in Esophageal Cancer Survivors

\section{Martin Dempster}

School of Psychology, Queen's University Belfast, N. Ireland, UK, BT7 1NN

Noleen K. McCorry

Marie Curie Cancer Care, Marie Curie Hospice Belfast, N.Ireland, UK, BT5 6NF

Emma Brennan

School of Psychology, Queen's University Belfast, N. Ireland, UK, BT7 1NN

Michael Donnelly, Liam Murray

School of Medicine \& Dentistry, Queen's University Belfast, N. Ireland, UK, BT7 1NN

Brian T. Johnston

Royal Group of Hospitals, Belfast Health \& Social Care Trust, N. Ireland, UK, BT12

$6 \mathrm{BJ}$

Corresponding author:

Martin Dempster, School of Psychology, Queen's University Belfast, University Road, Belfast, Northern Ireland, BT7 1NN.

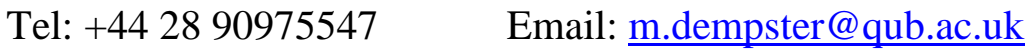

Author Contributions: All authors contributed to the conceptualization and design of the research and to the completion of the written article. Additionally, E Brennan managed the data collection and M Dempster and N McCorry led the data analysis. 


\begin{abstract}
Leventhal's Common Sense Model has provided a useful framework for explaining psychological distress in several chronic illnesses. The model indicates that a person's perception of their illness and their coping strategies are key determinants of their experience of psychological distress. The present research examines whether illness perceptions and coping strategies are related to levels of psychological distress among survivors of esophageal cancer. Everyone registered with the Oesophageal Patients' Association in the UK was mailed a questionnaire booklet which included the Illness Perception Questionnaire-Revised, the Cancer Coping Questionnaire and the Hospital Anxiety and Depression Scale. Complete responses were received from 484 people. Regression models indicated that the variables measured could explain $51 \%$ of the variance in anxiety and $42 \%$ of the variance in depression. Perceptions of esophageal cancer explained the majority of this variance. Positive focus coping strategies were also found to be important in explaining psychological distress. The results of this study are consistent with previous research demonstrating that illness perceptions are stronger correlates of adaptive outcomes than coping strategies. The findings suggest that cognition-based interventions could potentially be most effective in minimizing emotional distress among survivors of esophageal cancer.
\end{abstract}

Keywords: Esophageal cancer; depression; anxiety; psychological adaptation 


\section{Introduction}

The role of psychological factors in the well-being of people with cancer has been well documented. For example, breast cancer patients at comparable stages in their illness but who had high levels of hopelessness and depression did not survive as long as patients without these emotions $(1,2)$; and depression has been associated with poorer survival times for people with lung cancer (3). Therefore, it appears that improving or at least maintaining the psychological well-being of people with cancer may have beneficial effects (4). Thus, it is important to investigate the factors contributing to poor psychological health in order to inform the design of effective psychosocial interventions. Yet, little is known about the psychological health of esophageal cancer survivors or the factors that influence their psychological distress.

Research among people with cancer (particularly focused on women with breast cancer) indicates that anxiety and depression are associated with the type of coping strategies adopted and the person's perceptions of their cancer (5-8). Consequently, Leventhal's Common Sense Model (9) may be a useful approach to clarifying the interrelationships among these cognitive and emotional constructs.

Leventhal's Common Sense Model (CSM) suggests that when an individual is confronted with an illness or condition, they will attempt to assign meaning to this illness by accessing their perceptions about the illness. These illness perceptions will be influenced by the individual's emotional state and their emotional state will be influenced by their perceptions of the illness. The CSM proposes that, in an effort to restore normal functioning, individuals will develop coping strategies (based on their illness perceptions and emotional state), which will then be evaluated in terms of their success in restoring equilibrium. The result of this evaluation may be a change in coping 
strategy and/or a change in perceptions about the illness. In summary, the model suggests that a person's perceptions about an illness and their coping strategies can have an impact on their psychological well-being.

Research using quantitative methodologies has tended to focus on the illness perceptions component of the model and there is a growing body of research demonstrating strong relationships between illness perceptions and (physical and psychological) health outcomes $(10,11)$. Illness perceptions (as assessed by the Illness Perception Questionnaire-Revised (12)) are mental representations of illness by the individual within various domains: time line (acute/chronic), time line (cyclical), personal control, treatment control, consequences, cause and illness coherence.

Illness perceptions have been shown to explain a significant proportion of the variance in psychological distress in head and neck cancer $(13,14)$ and in breast cancer (15), even after controlling for disease-related variables. However, the nature of the relationships between illness perceptions and psychological distress differed between the different types of cancer. This clearly suggests that the factors which may impact on psychological health are specific to the type of cancer of interest. However, no published research has examined the relationship between illness perceptions and psychological distress among people with esophageal cancer.

The research presented here investigates the extent to which illness perceptions explain psychological distress (in terms of anxiety and depression symptoms) relative to demographic and biomedical variables, among survivors of esophageal cancer; and examines the nature and degree to which coping strategies influenced or mediated these relationships. 


\section{Materials and Methods}

Participants were recruited via the Oesophageal Patients' Association (OPA) UK database. The OPA is a patient support group formed to help patients and their families cope with the difficulties arising from the treatment associated with esophageal cancer. A total of 2,185 people on the OPA database were mailed a questionnaire booklet containing items relating to demographic information (sex, age, and whether there was someone in their life who they would label a "carer"), medical history (time since diagnosis, number of other illnesses / conditions, number of symptoms experienced during the previous month that were considered to be related to esophageal cancer) and the following questionnaires:

Illness Perception Questionnaire - Revised (IPQ-R). This questionnaire was used to assess the following illness perceptions: time line acute/chronic, time line cyclical, personal control, treatment control, consequences, cause and illness coherence. Higher scores on the personal control and treatment control scales indicate that the patient has a stronger belief in the effectiveness of their ability or their treatment to control the symptoms of their condition; higher scores on the consequences scale suggest that the patient perceives more severe consequences of their condition; higher scores on the illness coherence scale indicate that the patient has a clearer understanding of their condition; higher scores on the identity scale mean that the patient associates a higher number of symptoms with their condition; higher scores on the timeline acute/chronic and timeline cyclical scales indicate a stronger belief that the condition is chronic (rather than acute) and goes through cycles of getting better and worse rather than remaining stable. The 18 items which measure the person's perceptions of the causes of their esophageal cancer were factor analyzed (in line with the questionnaire 
authors' suggestion) and were found to load on 3 factors, which were labeled emotional causes (e.g. stress or worry), behavioral causes (e.g. smoking or alcohol) and externalized causes (e.g. hereditary or a virus). Higher scores on the cause scales indicate a stronger belief that this was a cause of their esophageal cancer. The IPQ-R has sound psychometric properties, with evidence for construct, discriminant and predictive validity and for internal and test-retest reliability (12).

The Cancer Coping Questionnaire (CCQ) (16). This is a 21 item questionnaire which assesses 5 dimensions: reflection/relaxation coping, positive focus, diversion, planning and use of interpersonal support. Higher scores on each scale indicate that this coping strategy is used more often. Psychometric properties are sound (16).

Hospital Anxiety and Depression Scale (HADS) (17). This is a 14 item scale which is divided into two dimensions - anxiety ( 7 items) and depression ( 7 items). Respondents choose one from four responses to each item. Their responses are then summed within dimensions and a total score for each dimension is obtained, with higher scores representing higher levels of anxiety and depression. Scores for the anxiety dimension and the depression dimension are categorized as follows: 0-7: normal, 8-10: mild, 11-14: moderate, 15-21: severe. The HADS has been validated among a population of people with cancer (18) and is the most frequently used screening tool for psychological distress in cancer care (19). A review of the optimal cut-off values for the HADS indicates that a score of 8 or more should be used to provide an appropriate balance of sensitivity and specificity (approximately 0.8 in each case), when assessed against the structured clinical interview based on the DSM criteria (20).

Ethical approval was obtained from the University Ethics Committee. Statistical Analysis 
To address the study aim, 2 hierarchical logistic regression analyses were conducted - 1 for each outcome (anxiety and depression). Medical and demographic variables were entered into the regression models in block 1; illness perceptions were entered in block 2; and the coping variables were entered in block 3 . In this way, we were able to determine the additional contribution to the explanation of variance in the outcome variable made by each block of variables. Additionally, this strategy allowed us to examine whether the addition of the coping variables changed the regression coefficients of the illness perception variables. If so, this would suggest that coping variables could be playing a mediating role in the model and would highlight the need for further analyses to explore this potential mediation.

\section{Results}

Of the 2,185 people who were mailed questionnaires, 594 responded (27\% response rate). A total of 68 respondents were excluded from the analyses because a diagnosis of esophageal cancer had not been confirmed (53/594 reported a diagnosis of Barrett's Esophagus and 15/594 did not provide a clear indication of their diagnosis). Of the remaining 526 respondents, 484 provided complete data on all the questionnaires.

Respondents were, on average, 65 years old $(\mathrm{SD}=9.94)$ and approximately $66 \%$ (319/484) were male. They had received a diagnosis of esophageal cancer for a median time of 45 months prior to completing the questionnaire. Based on available statistics about esophageal cancer in the UK (64\% male) (21), the sample in this study appear to be representative of the gender split of people with a diagnosis of esophageal cancer in the UK. 
In terms of psychological distress, $36 \%$ (174/484) of the sample met the criteria for probable anxiety and $24 \%$ (118/484) met the criteria for probable depression. Descriptive statistics for the other variables suggest that, on average, respondents perceive their condition to be chronic, caused mainly by events over which they had no control and they expect it to have adverse consequences for their life. However, the respondents report having a reasonably good understanding of their condition and they believe that both they and the medical profession can control their condition (see Table 1).

Point-biserial correlations between the illness perceptions and coping strategies and the psychological distress measures are shown in Table 2. Although some of the correlations are weak, most of the assessed perceptions of esophageal cancer have a statistically significant association with psychological distress. There are only weak associations between the different coping strategies and depression. For anxiety, the more a patient reports engaging in the reflection/relaxation, diversion or interpersonal coping strategies, the more likely they are to experience clinically significant levels of anxiety (see Table 2).

When regression models were generated, conclusions about the statistical significance of the regression coefficients for the medical/demographic variables and illness perceptions were not influenced by the addition of the coping variables. This suggested that coping strategies were not playing a mediating role in the model and therefore the final regression model only is presented in each case.

The regression model specified in Table 3 correctly classified $80 \%$ of the sample as anxious or not anxious $\left(\chi^{2}=223.785, \mathrm{p}<.001\right)$. The medical and demographic variables contributed $16.5 \%$ of the variance explained and the illness cognitions 
variables contributed an additional 22\%; with the coping variables contributing the remaining $12 \%$.

The regression model specified in Table 4 correctly classified $82 \%$ of the sample as depressed or not depressed $\left(\chi^{2}=158.846, \mathrm{p}<.001\right)$. The medical and demographic variables contributed $11.5 \%$ of the variance explained and the illness cognitions variables contributed an additional 23.5\%; with the coping variables contributing the remaining $7 \%$.

\section{Discussion}

The research presented here indicates that over one-third of esophageal cancer survivors could be experiencing clinically significant levels of psychological ill health, particularly anxiety. This is similar to levels of distress reported for people with other head and neck cancers $(14,22)$ but higher than rates reported for other breast, prostate, bronchial and gastrointestinal cancers $(23,24)$. It is possible that the higher rates of psychological ill-health can be explained by the consequences of esophageal and head and neck cancer, which have a potential impact on appearance and/or social functioning (such as dining with others) (25). However, no previously published research exists which has examined the factors that help us to explain psychological well-being among esophageal cancer survivors.

In our sample, younger people and people without someone they could call a "carer" were more likely to be anxious, and people with other illnesses were more likely to be depressed. However, after controlling for these variables, the illness perceptions and coping variables contributed the majority of the explained variance in psychological distress. 
Specifically, respondents were less likely to report poor psychological health when they: perceived less severe consequences from their condition; were more likely to believe that they understand their condition; and were less likely to believe that their esophageal cancer was caused by stress or poor emotional health. Additionally, maintaining a positive focus appears to minimize psychological harm, whereas spending more time relaxing and reflecting (in order to cope with their condition) is associated with poor psychological health.

Furthermore, respondents who were more likely to report engaging in diversionary coping strategies were also more likely to be anxious, and the more that respondents believed they had control over their condition, the less likely they were to be depressed.

The results support the hypothesis that individuals' personal beliefs about esophageal cancer play a significant role in their adjustment to the condition, even when the effects of medical and demographic variables are taken into account. However, there was little evidence to support the role of coping as a mediator between illness perceptions and psychological distress.

In summary, it appears that in order to optimize psychological health among survivors of esophageal cancer, it would be useful to develop interventions which focused on illness perceptions and coping. The illness perceptions which need to be targeted are perceptions of: consequences, cause, control and understanding of the condition. Providing clear and coherent information about esophageal cancer is, therefore, perhaps an important protective factor against psychological distress. In addition, positive focus coping strategies need to be facilitated and reflection and diversionary coping strategies should be discouraged. Diversionary coping 
strategies might be, for example, channeling energies into other activities, such as housework, gardening or other physical activity as a way of avoiding thoughts about cancer. Avoidant coping strategies such as these have, for some time, been shown to be ineffective long term solutions to dealing with chronic illness (26). To ensure a focus on positive focus coping strategies and a discouragement of diversionary coping strategies, various psychosocial interventions could be implemented. Most of these interventions require a skilled practitioner to encourage the patient to restructure their cognitions. An example is the positive self-talk approach $(27,28)$. Positive self-talk can be encouraged in patients by assisting them to identify events that result in negative thoughts and the negative emotions associated with these thoughts and then developing a strategy to stop these thoughts. These thoughts are then replaced by appropriate positive statements that the patient rehearses and an action plan for initiating the rehearsal of these statements. Through this process, patients can ultimately replace the negative thoughts with positive ones, thereby replacing negative emotions with, at least, neutral and, at best, positive emotions.

The results of this study are consistent with previous research demonstrating that illness perceptions are stronger correlates of adaptive outcomes than coping scores $(11,29,30)$, thereby suggesting that cognition-based interventions could potentially be most effective in minimizing emotional distress. However, longitudinal research is required to examine the relationship between changes in cognitions and changes in psychological distress, prior to an investment in an intervention trial. Some initial longitudinal work among people with head and neck cancer indicates that an intervention based on illness perceptions may be useful for increasing quality of life (14), and some information guiding the design of illness perception based interventions 
in head and neck cancer have recently been published (31). These interventions draw heavily on the principles of cognitive behavioral therapy and could be adapted to address the specific illness perceptions highlighted in the research presented here. Therefore, we suggest that this approach may be a useful method of addressing psychological ill-health among survivors of esophageal cancer.

In conclusion, it is important to note that most survivors of esophageal cancer are in good psychological health and do not require formal interventions. Furthermore, the sample in this study may have been biased towards those who are experiencing poor psychological health and/or were better educated about their condition and were, therefore, more willing to participate in the research. Unfortunately, given the anonymous nature of the survey, a comparison of responders with non-responders was not possible. Nevertheless, a sizeable proportion of esophageal cancer survivors have clinically significant symptoms of anxiety and/or depression that can largely be explained by their perceptions of esophageal cancer. These perceptions are modifiable and, therefore, appropriately tailored and targeted interventions could have beneficial effects for the quality of life of survivors of esophageal cancer. 


\section{Acknowledgements}

This research was supported by a grant from Action Cancer, Northern Ireland and facilitated by David Kirby and staff at the Oesophageal Patients' Association UK.

There are no conflicts of interest for any authors. 


\section{References}

1 Pettingale K, Morris T, Greer S, Haybittle J. Mental attitudes to cancer: an additional prognostic factor. Lancet 1985; 325: 750.

2 Watson M, Haviland J, Greer S, Davidson J, Bliss J. Influence of psychological response on survival in breast cancer: a population-based cohort study. Lancet 1999; 354: 1331-36.

3 Faller H, Bülzebruck H, Drings P, Lang H. Coping, distress and survival among patients with lung cancer. Arch Gen Psychiatry 1999; 56: 756-62. 4 Satin JR, Linden W, Phillips MJ. Depression as a predictor of disease progression and mortality in cancer patients: A meta-analysis. Cancer 2009; 115: 534961.

5 Carver CS, Pozo C, Harris SD et al. How coping mediates the effect of optimism on distress: A study of women with early stage breast cancer. J Personality Soc Psychol 1993; 65: 375-90.

6 Osowiecki D, Compas BE. Psychological adjustment to cancer: Control beliefs and coping in adult cancer patients. Cognitive Therapy Res 1998; 22: 483-99. 7 Schou I, Ekeberg O, Ruland CM, Sandvik L, Karesen R. Pessimism as a predictor of emotional morbidity one year following breast cancer surgery. Psycho-Oncol 2004; 13: 309-20.

8 Watson M, Greer S, Rowden L et al. Relationships between emotional control, adjustment to cancer and depression and anxiety in breast cancer patients. Psychol Med 1991; 21: 51-57.

9 Leventhal H, Meyer D, Nerenz D. The common sense representation of illness 
danger. In: Rachman S (ed.) Medical Psychology, vol. 2. New York: Pergamon Press, 1980; 7-30.

10 Cameron LD, Moss-Morris R. Illness-related cognition and behaviour. In: Kaptein A, Weinman J. (eds.) Health Psychology, Oxford: BPS Blackwell, 2004; 84-110.

11 Dorrian A, Dempster M, Adair P. Adjustment to inflammatory bowel disease:

The relative influence of illness perceptions and coping. Inflamm Bowel Dis 2009; 15: 47-55.

12 Moss-Morris R, Weinman J, Petrie KJ, Horne R, Cameron LD, Buick D. The revised Illness Perception Questionnaire (IPQ-R). Psychol Health 2002; 17: 1-16.

13 Scharloo M, Baatenburg de Jong R, Langeveld TPM, van Velzen-Verkaik RN, Doorn-op den Aaker MM, Kaptein AA. Quality of life and illness perceptions in patients with recently diagnosed head and neck cancer. Head Neck 2005; 27: 857-63. 14 Llewellyn CD, McGurk M, Weinman J. Illness and treatment beliefs in head and neck cancer: Is Leventhal's common sense model a useful framework for determining changes in outcome over time? J Psychosom Res 2007; 63: 17-26.

15 Miller K, Purshotham AD, McLatchie E, George D, Murray GD. A 1-year prospective study of individual variation in distress and illness perceptions after treatment for beast cancer. J Psychosom Res 2005; 58: 335-42.

16 Moorey S, Frampton M, Greer S. The Cancer Coping Questionnaire: A selfrating scale for measuring the impact of adjuvant psychological therapy on coping behavior. Psycho-Oncol 2003; 12: 331-44.

17 Snaith RP, Zigmond AS. The Hospital Anxiety and Depression Scale. Acta Psychiatrica Scand 1983; 67: 361-70. 
18 Smith AB, Selby PJ, Velikova G et al. Factor analysis of the Hospital Anxiety and Depression Scale from a large cancer population. Psychol Psychotherapy 2002; 75: 16576.

19 Reuter K, Härter M. Screening for mental disorders in cancer patients - discriminant validity of HADS and GHQ12 assessed by standardized clinical interview. Int J Methods Psychiatric Res 2001; 10: 86-96.

20 Bjelland I, Dahl AA, Haug TT, Neckelmann D. The validity of the Hospital Anxiety and Depression Scale: An updated literature review. J Psychosom Res 2002; 52: 6977. 21 Cancer Research UK. UK Oesophageal Cancer Statistics. Available from URL: http://info.cancerresearchuk.org/cancerstats/types/oesophagus/index.htm [accessed January 25, 2011].

22 Hodges LJ, Humphris GM. Fear of recurrence and psychological distress in head and neck cancer patients and their carers. Psycho-Oncol 2009; 18: 841-48.

23 Frick E, Tyroller M, Panzer M. Anxiety, depression and quality of life of cancer patients undergoing radiation therapy: A cross-sectional study in a community hospital outpatient centre. Eur J Cancer Care 2007; 16: 130-36.

24 Nordin K, Glimelius B. Predicting delayed anxiety and depression in patients with gastrointestinal cancer. Br J Cancer 1999; 79: 525-29.

25 McCorry NK, Dempster M, Clarke C, Doyle R. Adjusting to life after esophagectomy: the experience of survivors and carers. Qual Health Res 2009; 19: 1485-94.

26 Deimling GT, Wagner LJ, Bowman KF et al. Coping among older adult long term cancer survivors. Psycho-Oncol 2006; 15: 143-59. 
27 Boutin DL. Effectiveness of cognitive behavioral and supportive-expressive group therapy for women diagnosed with breast cancer: a review of the literature. J Spec Group Work 2007; 32: 267-84.

28 Zaza C, Sellick SM, Hillier LM. Coping with cancer: what do patients do? J Psychosoc Oncol 2005; 3: 55-73.

29 Heijmans M. The role of patients' illness representations in coping and functioning with Addison's Disease. Br J Health Psychol 1999; 4: 137-49.

30 Rozema H, Völlnick T, Lechner L. The role of illness representations in coping and health of patients treated for breast cancer. Psycho-Oncol 2009; 18: 849-57.

31 Humphris G, Ozakinci G. The AFTER intervention: A structured psychological approach to reduce fears of recurrence in patients with head and neck cancer. $\mathrm{Br} \mathbf{J}$ Health Psychol 2008; 13: 223-30. 
Table 1: Descriptive Statistics

\begin{tabular}{lll}
\hline & Mean (SD) & Midpoint \\
\hline CCQ Reflection/relaxation & $9.50(3.19)$ & 12.5 \\
CCQ Positive focus & $8.30(2.32)$ & 7.5 \\
CCQ Diversion & $6.43(2.20)$ & 7.5 \\
CCQ Planning & $7.77(2.57)$ & 7.5 \\
CCQ Interpersonal & $14.10(5.35)$ & 17.5 \\
IPQ Acute/chronic timeline & $22.83(4.68)$ & 18 \\
IPQ Cyclical timeline & $12.00(3.64)$ & 14 \\
IPQ Consequences & $20.82(4.90)$ & 18 \\
IPQ Personal control & $19.97(4.73)$ & 18 \\
IPQ Treatment control & $17.04(3.61)$ & 15 \\
IPQ Illness coherence & $19.31(4.33)$ & 15 \\
IPQ Emotional cause & $11.99(3.96)$ & 15 \\
IPQ Behavioural cause & $10.38(3.66)$ & 12 \\
IPQ Externalized cause & $15.02(3.41)$ & 12 \\
\hline
\end{tabular}


Table 2: Point-biserial correlations (and significance values) between illness perceptions and psychological well-being

\begin{tabular}{llll}
\hline & Anxiety & Depression \\
\hline IPQ Acute/chronic timeline & $0.116 \quad(.011)$ & $0.130 \quad(.004)$ \\
IPQ Cyclical timeline & $0.229(<.001)$ & $0.181 \quad(<.001)$ \\
IPQ Consequences & $0.309(<.001)$ & $0.305(<.001)$ \\
IPQ Personal control & $-0.106 \quad(.020)$ & $-0.235 \quad(<.001)$ \\
IPQ Treatment control & $-0.186(<.001)$ & $-0.226(<.001)$ \\
IPQ Illness coherence & $-0.274(<.001)$ & $-0.277 \quad(<.001)$ \\
IPQ Emotional cause & $0.347(<.001)$ & $0.240(<.001)$ \\
IPQ Behavioural cause & $0.111 \quad(.014)$ & $0.067 \quad(.143)$ \\
IPQ Externalized cause & $0.017 \quad(.715)$ & $0.028 \quad(.534)$ \\
CCQ Reflection/relaxation & $0.327(<.001)$ & $0.133 \quad(.003)$ \\
CCQ Positive focus & $-0.017 \quad(.710)$ & $-0.193 \quad(<.001)$ \\
CCQ Diversion & $0.327(<.001)$ & $0.103 \quad(.024)$ \\
CCQ Planning & $0.079 \quad(.084)$ & $-0.045 \quad(.328)$ \\
\hline & $0.249(<.001)$ & $0.078 \quad(.088)$ \\
\hline
\end{tabular}


Table 3: Logistic regression analysis with patient anxiety as the outcome variable

\begin{tabular}{|c|c|c|c|c|c|}
\hline & B & Wald & $\mathrm{p}$ & Odds & $95 \%$ C.I. \\
\hline & & \multicolumn{4}{|c|}{ Ratio } \\
\hline Sex (male) & -.482 & 2.750 & .097 & .618 & $.350-1.092$ \\
\hline Age & -.066 & 15.849 & $<.001$ & .936 & $.906-.967$ \\
\hline No. of months since diagnosis & $<.001$ & .006 & .937 & 1.000 & $.995-1.005$ \\
\hline Other illnesses or medical conditions & -.454 & 2.990 & .084 & .635 & $.380-1.062$ \\
\hline No. of symptoms experienced & .020 & .186 & .666 & 1.020 & $.933-1.116$ \\
\hline Relationship with carer & & 6.673 & .036 & & \\
\hline Carer Spouse/Partner & .278 & .440 & .507 & 1.321 & $.580-3.007$ \\
\hline Carer Other & 1.557 & 6.076 & .014 & 4.746 & $1.376-16.371$ \\
\hline IPQ Acute/chronic timeline & -.009 & .064 & .800 & .991 & $.925-1.062$ \\
\hline IPQ Cyclical timeline & .009 & .054 & .816 & 1.009 & $.933-1.092$ \\
\hline IPQ Consequences & .088 & 6.735 & .009 & 1.092 & $1.022-1.168$ \\
\hline IPQ Personal control & -.043 & 1.709 & .191 & .958 & $.897-1.022$ \\
\hline IPQ Treatment control & -.037 & .665 & .415 & .964 & $.882-1.053$ \\
\hline IPQ Illness coherence & -.128 & 11.250 & .001 & .880 & $.817-.948$ \\
\hline IPQ Emotional cause & .143 & 14.193 & $<.001$ & 1.154 & $1.071-1.244$ \\
\hline IPQ Behavioural cause & .018 & .187 & .666 & 1.018 & $.939-1.104$ \\
\hline IPQ Externalized cause & -.105 & 6.104 & .013 & .900 & $.828-.978$ \\
\hline CCQ Reflection/relaxation & .212 & 12.651 & $<.001$ & 1.237 & $1.100-1.390$ \\
\hline CCQ Positive focus & -.400 & 18.763 & $<.001$ & .670 & $.559-.803$ \\
\hline CCQ Diversion & .310 & 15.560 & $<.001$ & 1.363 & $1.169-1.589$ \\
\hline CCQ Planning & .026 & .126 & .723 & 1.026 & $.889-1.185$ \\
\hline
\end{tabular}


CCQ Interpersonal

$\begin{array}{llll}.050 & 2.794 & .095 & 1.052\end{array}$

$.991-1.115$

Constant

3.684

2.910

.088

39.823 
Table 4: Regression analysis with patient depression as the outcome variable

\begin{tabular}{|c|c|c|c|c|c|}
\hline & B & Wald & $\mathrm{p}$ & Odds & $95 \%$ C.I. \\
\hline & & \multicolumn{4}{|c|}{ Ratio } \\
\hline Sex (male) & .146 & .223 & .637 & 1.158 & $.630-2.127$ \\
\hline Age & -.005 & .075 & .784 & .996 & $.964-1.028$ \\
\hline No. of months since diagnosis & $<.001$ & .043 & .837 & .999 & $.994-1.005$ \\
\hline Other illnesses or medical conditions & -.654 & 5.668 & .017 & .520 & $.303-.891$ \\
\hline No. of symptoms experienced & .099 & 4.160 & .041 & 1.104 & $1.004-1.215$ \\
\hline Relationship with carer & & 2.700 & .259 & & \\
\hline Carer Spouse/Partner & -.581 & 1.895 & .169 & .559 & $.244-1.279$ \\
\hline Carer Other & .005 & .000 & .993 & 1.005 & $.305-3.311$ \\
\hline IPQ Acute/chronic timeline & -.027 & .528 & .467 & .973 & $.904-1.047$ \\
\hline IPQ Cyclical timeline & .030 & .488 & .485 & 1.030 & $.947-1.120$ \\
\hline IPQ Consequences & .143 & 13.410 & $<.001$ & 1.154 & $1.069-1.246$ \\
\hline IPQ Personal control & -.109 & 10.233 & .001 & .897 & $.839-.959$ \\
\hline IPQ Treatment control & -.018 & .156 & .693 & .982 & $.898-1.074$ \\
\hline IPQ Illness coherence & -.082 & 5.216 & .022 & .922 & $.859-.988$ \\
\hline IPQ Emotional cause & .082 & 4.497 & .034 & 1.085 & $1.006-1.170$ \\
\hline IPQ Behavioural cause & .020 & .218 & .640 & 1.020 & $.937-1.111$ \\
\hline IPQ Externalized cause & -.062 & 2.124 & .145 & .939 & $.864-1.022$ \\
\hline CCQ Reflection/relaxation & .156 & 6.261 & .012 & 1.169 & $1.034-1.321$ \\
\hline CCQ Positive focus & -.440 & 21.084 & $<.001$ & .644 & $.533-.777$ \\
\hline CCQ Diversion & .105 & 1.571 & .210 & 1.111 & $.942-1.310$ \\
\hline CCQ Planning & .080 & 1.105 & .293 & 1.083 & $.933-1.257$ \\
\hline
\end{tabular}


CCQ Interpersonal

$-.007$

.055

.815

$.993 \quad .936-1.054$

Constant

.702

.097

$.755 \quad 2.018$ 